\title{
CUSCO Y SUS ENCANTOS: MIRADAS SOBRE FIESTAS Y COLORES
}

\author{
Íris de Fátima Lima Barbosa ${ }^{1}$
}

Al salir del aeropuerto en Lima, el Pacífico te recibe con el olor más intenso de sus marejadas, su fuerza traspasa las piedras que las acoge al borde de su orilla, el movimiento que se produce en esa inmensidad de agua se convierte en una invitación casi imposible de resistir. Así es Lima, la capital peruana de aproximadamente 8. 445. 211 de habitantes, una ciudad compuesta de extremos en varios niveles, desde lo social a lo histórico y cultural, donde en sus calles reflejan la trayectoria de un pueblo demarcado entre la herencia de sus ancestros, como el imperio incaico y sus "conquistadores", el imperio español.

La herencia del imperio Inca o del Tawantinsuyo, como los quechuas nombraban a su mundo, que reproduce Lima, nos lleva a otro camino, a otra referencia en Perú, la ciudad de Cusco que en quechua Qosqo, significa "ombligo", o en su forma figurada, "centro" "o punto de encuentro", representando el lugar de donde partía una vasta red de caminos, es decir, el legendario camino del Inca.

Considerada la capital del Tawantinsuyo, Cusco aún preserva toda una representación de atmosfera histórica que recuerda el período de sus ancestros, desde de sus calles, iglesias, plazas, hasta el camino que lleva a Machu Picchu.

En ese "punto de encuentro" (Cusco) mientras lo recorría, fui recibida, acogida, por una ciudad en fiesta folclórica que celebraba con largos desfiles alrededor de la Plaza de Armas, representando espectáculos como la danza del "Qoyllur Riti”, celebración que ocurre después de 58 días pasados la Pascua, que se convierte en una mezcla, un sincretismo entre la cosmovisión andina y elementos del catolicismo introducido en esas tierras por los españoles.

En este ambiente conmemorativo, se presentan personajes como: Qhapaq Chunchu, que representa al habitante proveniente de las etnias de la selva, Qhapaq Qolla, personaje que representa al comerciante del altiplano que realizaba largos viajes a través de las cordilleras en dirección a los Valles, Qhapaq Negro, Mestiza Qoyacha, Auqa Chileno, Contradanza, Majeño, Sijllas, Kachampa, entre otros.

\footnotetext{
${ }^{1}$ Profesora de Lengua y Literaturas Hispanófonas en Universidade Federal do Pará (Brasil), Licenciada en Letras Lengua Portuguesa (Universidade Federal do Pará - UFPA) y Letras Lengua Española (Universidade da Amazonia - UNAMA), Especialista en Enseñanza de Lengua Portuguesa y Literaturas (Universidade Federal do Pará - UFPA), Magíster en Letras - Estudios Literarios (Universidade Federal do Pará - UFPA), estudiante de Doctorado en Literatura (Pontificia Universidad Católica de Chile - PUC). Correo electrónico: iris_flb@hotmail.com.
} 
Otra danza tradicional que era presentada durante el desfile se llama "Qhapaq Qolla", de género religioso - ceremonial, la danza proviene de la zona altiplánica del departamento de Puno y su término proviene del quechua que significa "rico habitante del Qollasuyo", denominado de esa forma por tener la lana más fina del Perú.

Relacionada con los comerciantes que llegaban a Cusco, la danza tradicional retrata al habitante altiplánico, cuyos animales de carga principales para ejercer sus actividades de comercio son los camélidos (llamas, alpacas, guanacos). Siempre cargados de productos de esa zona: Ch'arki, queso, qañihua, lana, fibra y otros mercancías, para luego internarse a los diferentes distritos y provincias.

En ese contexto, Cusco se configura como una ciudad histórica, de ricos sabores, lindos colores y danzas sincréticas, que se materializa, se entrelaza y se entrecruza en una red de historias y culturas.

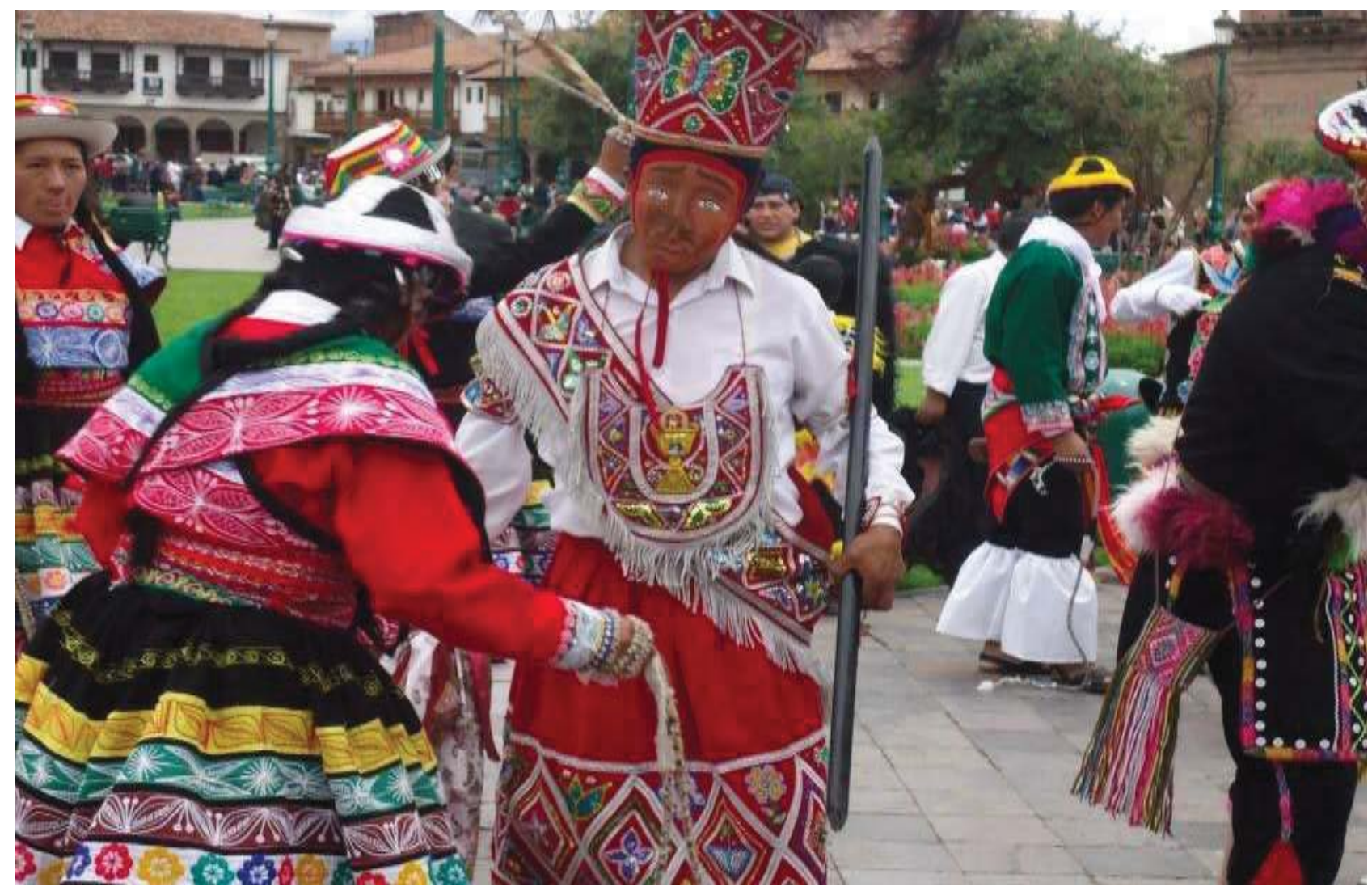



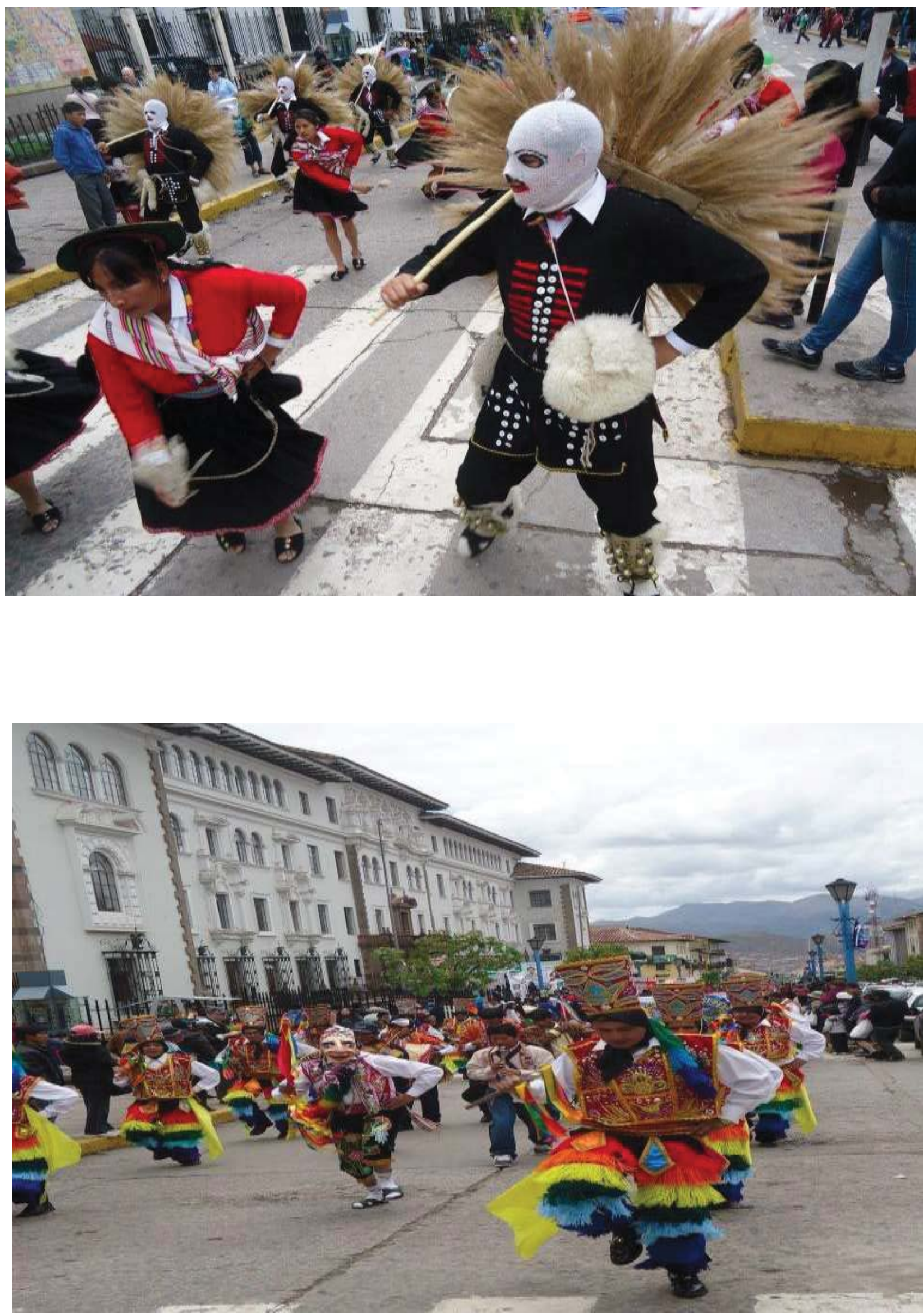

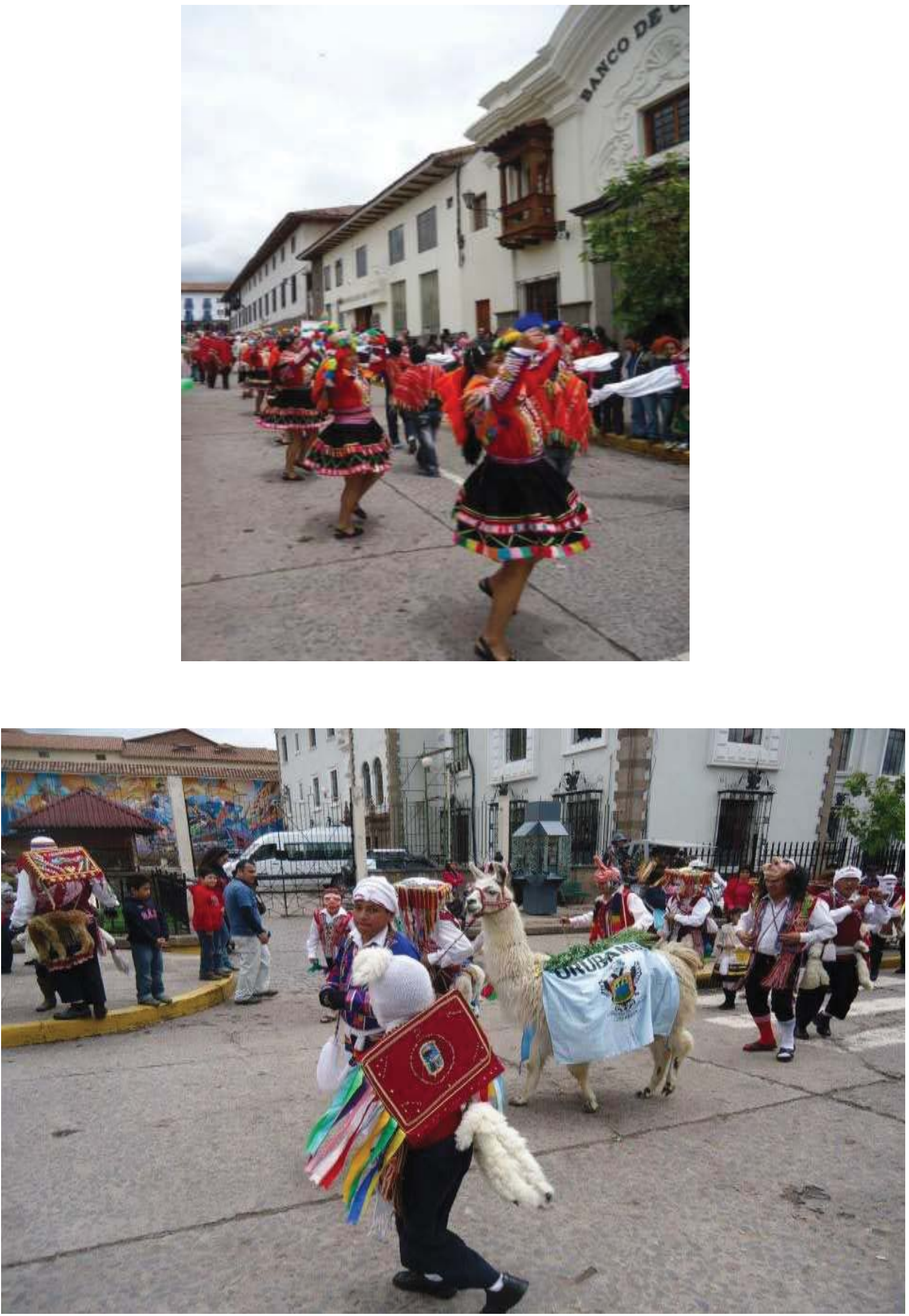

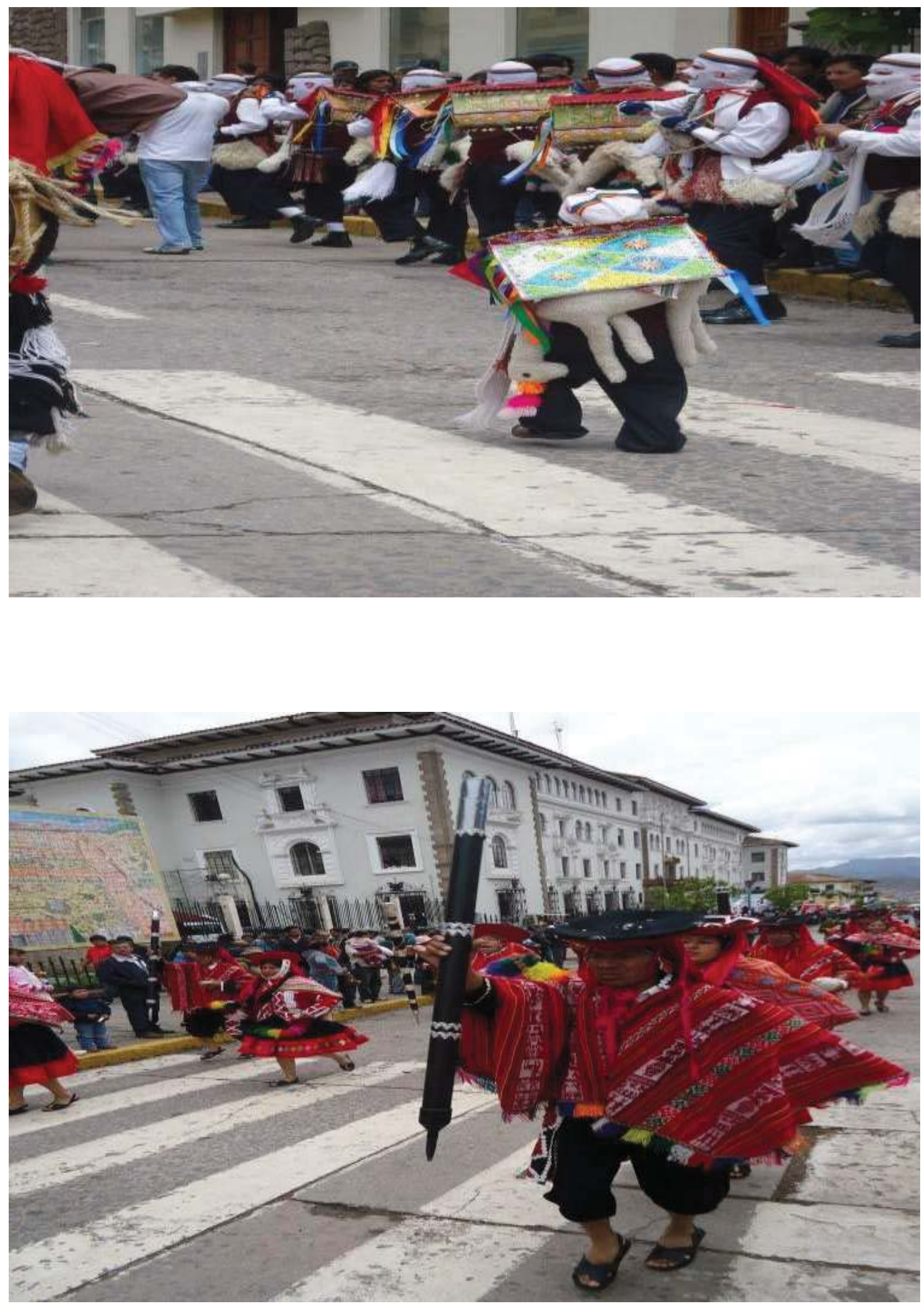

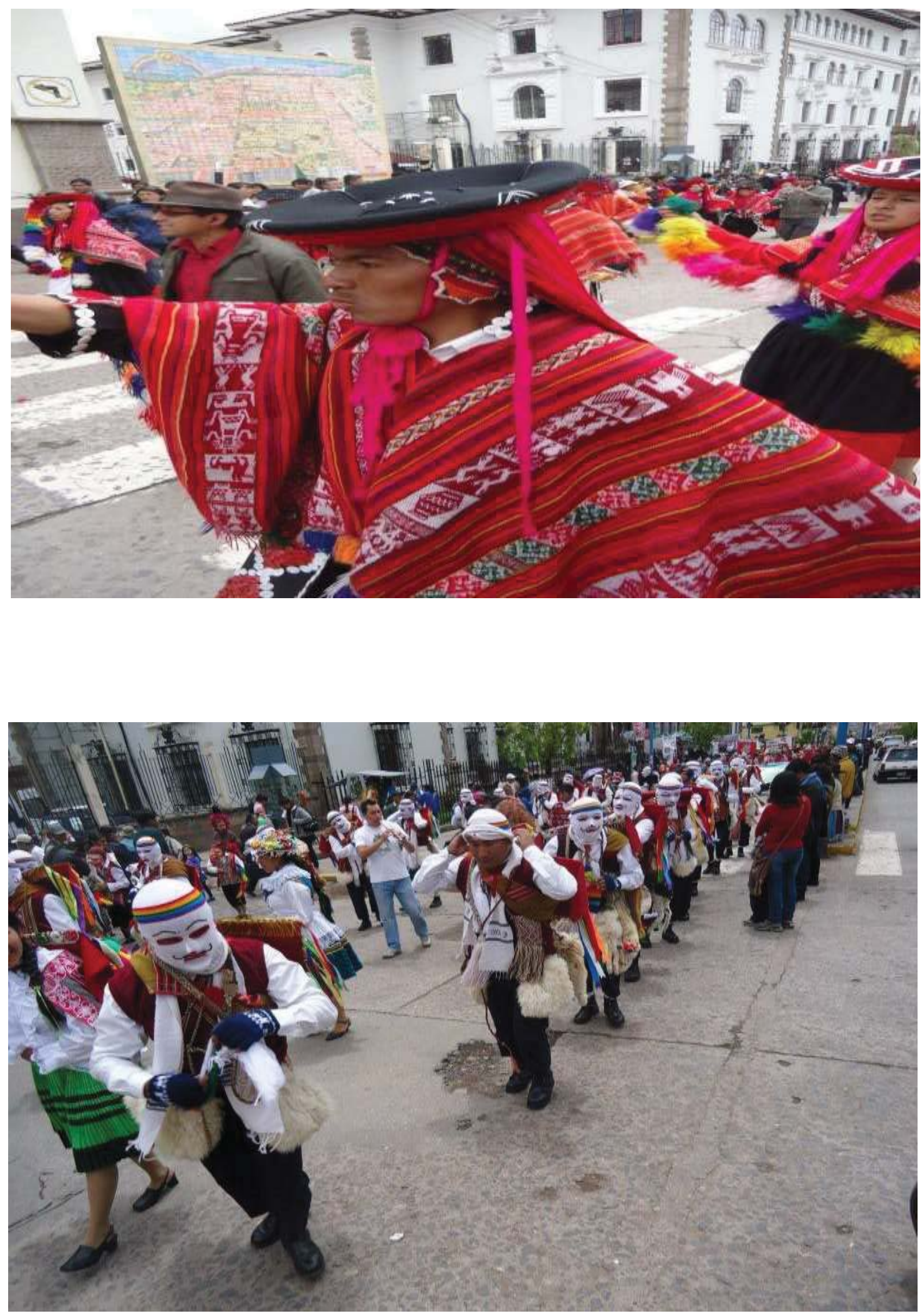

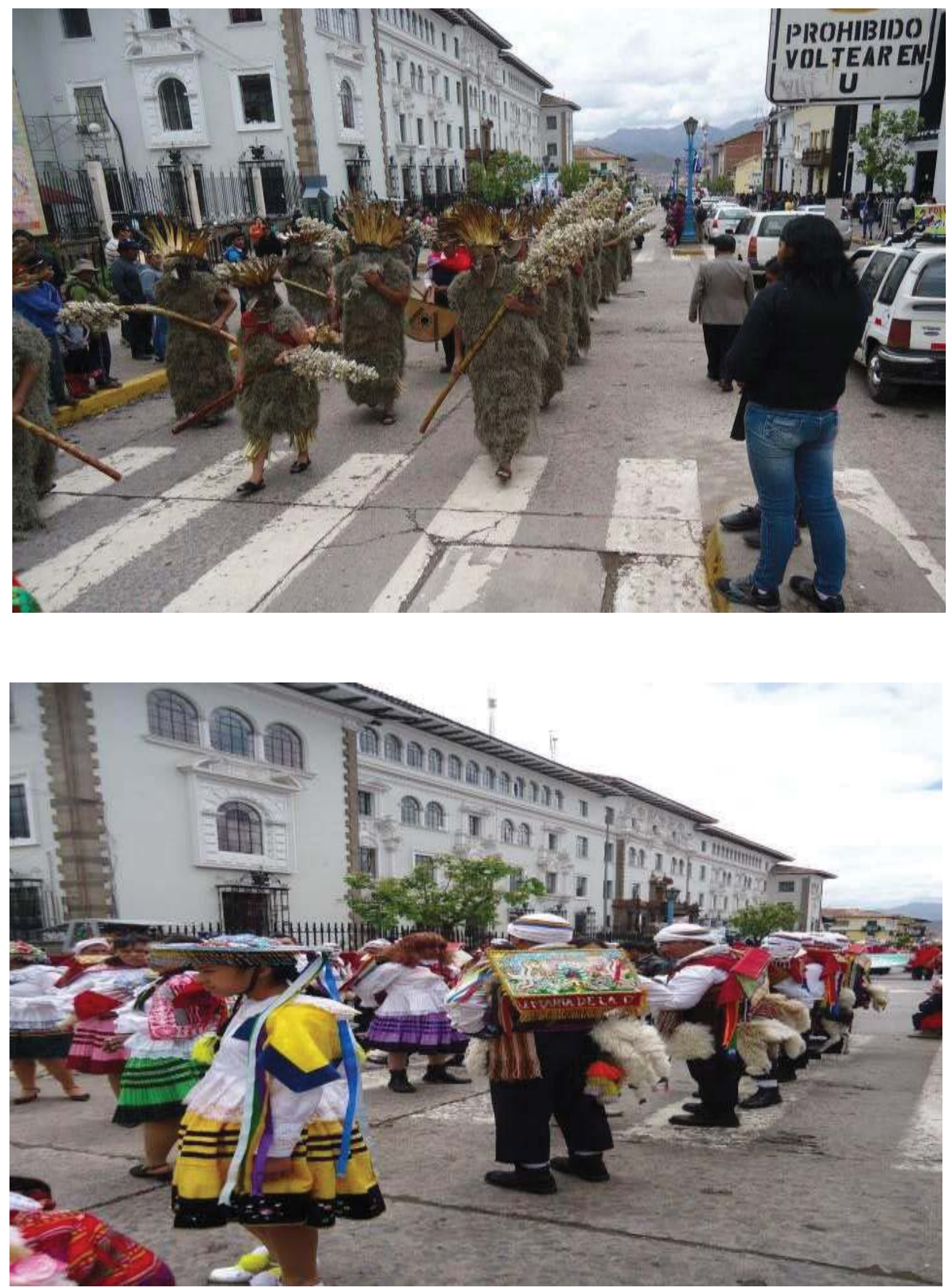

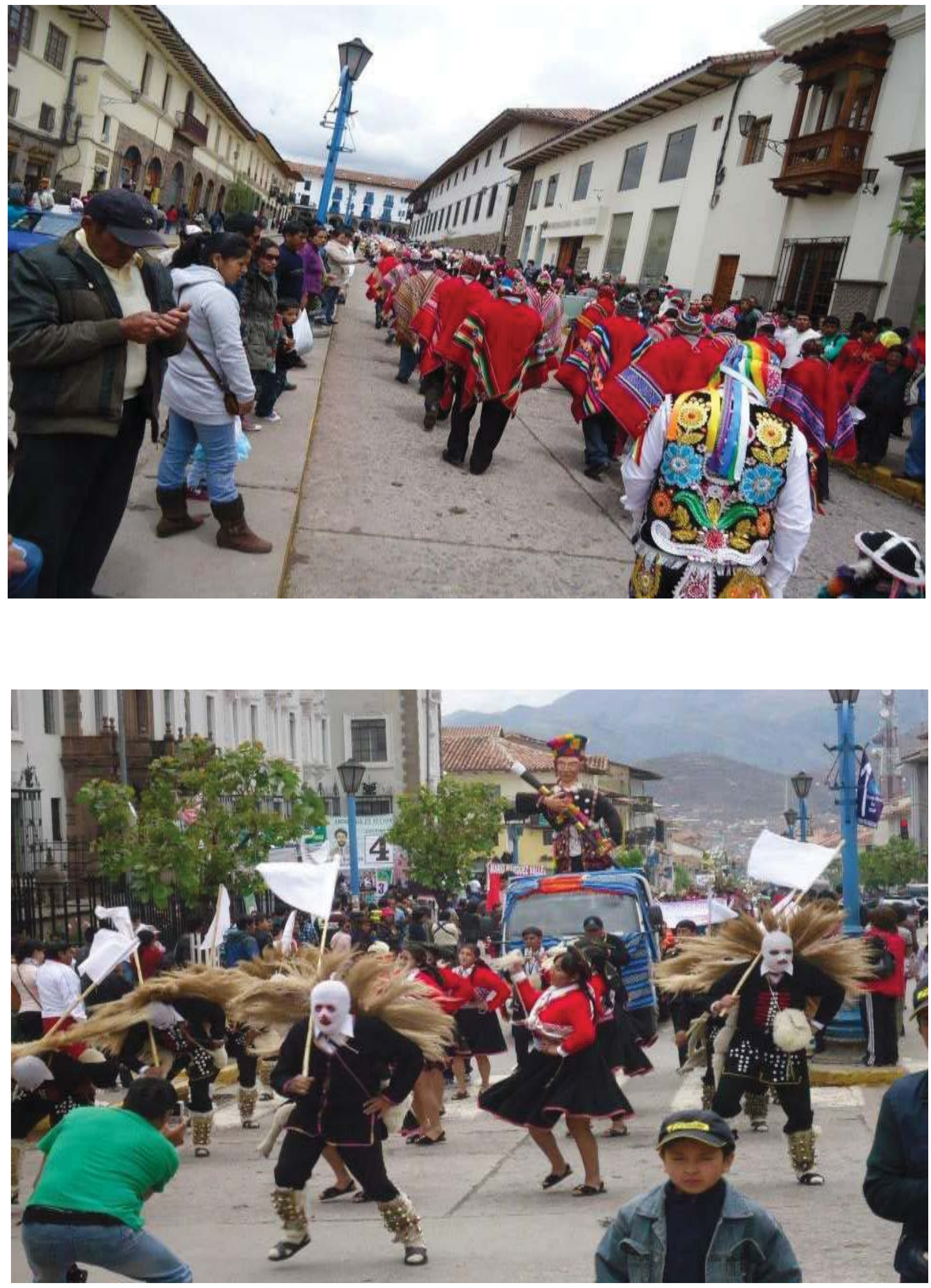

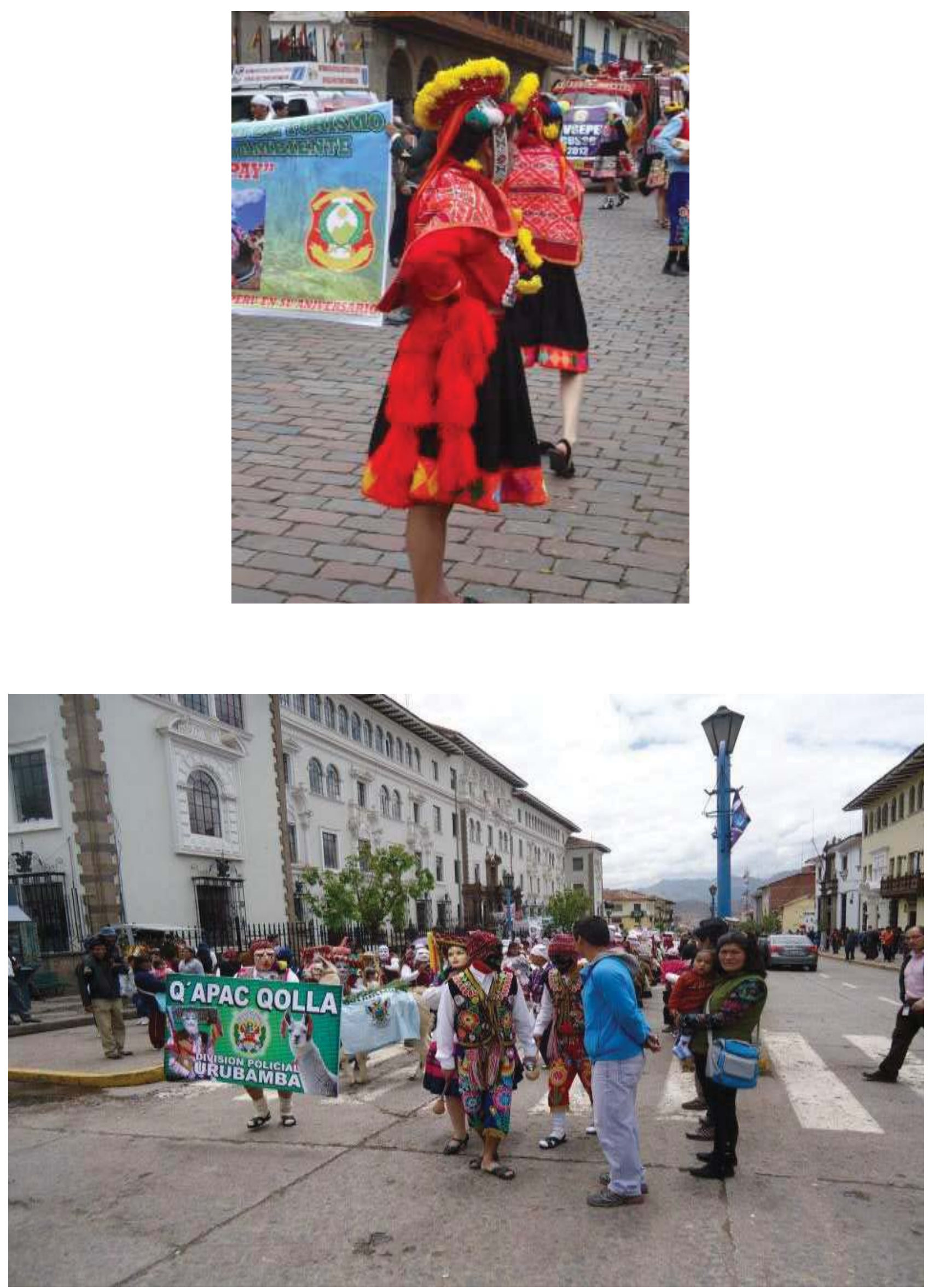